Editorial

\title{
Introduction to Visual Communication in the Age of Social Media: Conceptual, Theoretical and Methodological Challenges
}

\author{
Uta Russmann ${ }^{1, *}$ and Jakob Svensson ${ }^{2}$ \\ ${ }^{1}$ Department of Communication, Marketing \& Sales, FHWien der WKW University of Applied Sciences for Management \& \\ Communication, 1180 Vienna, Austria; E-Mail: uta.russmann@fh-wien.ac.at \\ 2 School of Arts \& Communication (K3), Malmö University, 20506 Malmö, Sweden; E-Mail: jakob.svensson@mah.se \\ * Corresponding author
}

Submitted: 15 November 2017 | Published: 21 December 2017

\begin{abstract}
This thematic issue of Media and Communication focuses attention on the shift towards visual images on social media as well as the transformation of visual communication which has occurred within the online ecology of social media platforms. The sharing of images is becoming an integral part of the social media experience today, and given that social media platforms are the prime locus for sociability-at least among young people in the West-this shift towards visuals arguably transforms how we relate to each other and the world around us, as well as how we perceive and construct our sense of self. For researchers, this raises conceptual, theoretical and methodological challenges. This thematic issue presents six articles as well as a book review on visual communication in social media focusing on developing a conceptual apparatus and precise definitions of objects and practices of study as well as contributions that address and discuss the methodological challenges as well as their potential solutions. The idea was to synergize research from a wide variety of communicationrelated disciplines on this rather new topic.
\end{abstract}

\section{Keywords}

images; Instagram; Facebook; practices; qualitative methods; Twitter; visual communication; visual social media

Issue

This editorial is part of the issue "Visual Communication in the Age of Social Media: Conceptual, Theoretical and Methodological Challenges", edited by Uta Russmann (FHWien der WKW University of Applied Sciences for Management \& Communication, Austria) and Jakob Svensson (Malmö University, Sweden).

(C) 2017 by the authors; licensee Cogitatio (Lisbon, Portugal). This article is licensed under a Creative Commons Attribution 4.0 International License (CC BY).

\section{Introduction}

With the rise of YouTube, Instagram and Snapchat there has been a shift towards visual images in the ecology of social media. Some of the most popular social media platforms in terms of usage primarily focus on visuals such as pictures and videos. More ubiquitous platforms like Facebook and Twitter have followed and highlighted visual images in their services as well. Indeed, the sharing of images is becoming an integral part of the social media experience today, and given that social media platforms are the prime locus for sociability-at least among young people in the West-this shift towards visuals arguably transforms how we relate to each other and the world around us, as well as how we perceive and construct our sense of self. This shift in social media practices is, according to Highfield and Leaver (2016) "requiring researchers to broaden and diversify the way social media is examined and addressed" (p. 49), as until recently, most research online focused on "text-only aspects of online communication or the structural elements like hyperlinks" (p. 48).

The visual image is a unique object (of research). Visual images are often understood as additional modes of communication complementing written or spoken textthey help the viewer to understand a message faster. Visual images also create meaning on their own and they often incorporate multiple meanings (Hand, 2017). 
Visual images suggest reality, create causal relationships and foster interaction (Fahmy, Bock, \& Wayne, 2014). Yet, to view this shift towards visual images on social media as merely the return of visual communication, would be to miss the point. Today social media platforms are becoming more multimodal as they now host pictures, videos, hashtags, emoticons as well as written text. On top of this, social media platforms also allow visual images to be framed, filtered and edited before being distributed. Hence, not only do online visuals add additional information to a message and elaborate on "who we are", they also afford highly strategic and reflexive communication in order to give a specific impression of the sender, an object or a place among other things.

This thematic issue of Media and Communication focuses attention on the shift towards visual images on social media as well as the transformation of visual communication which has occurred within the online ecology of social media platforms. This raises conceptual, theoretical and methodological challenges for researchers. For example, how do the online contexts of social media platforms transform visual communication and in which contexts is this particularly fruitful to study? What are the best practices for studying online visuals and how do we delineate and define images as an object of study or unit of analysis? For example, should we conceive an online visual image as static photography or as a locus of interaction?

To systemize approaches to visual communication on social media platforms as well as the articles in this thematic issue of Media and Communication, the framework by Rose (2016; first published in 2001) is helpful (for similar approaches see also Müller \& Geise, 2015, as well as Laestadius, 2017). Rose (2016) differentiate the sites "at which the meanings of an image are made" (p. 24): The site(s) of production (referring to where an image is made); the site(s) of the image itself (referring to its visual content); the site(s) of its circulation (referring to where an image travels) as well as site(s) where the image encounters its spectators or users, something Rose (2016) labels audiencing. At each of these sites, there are three modalities (aspects): the technological, the compositional, and the social (Rose, 2016). As with all analytical delineations, these sites may intersect and overlap (as shown in some of the articles included in this thematic issue). The site of the (material) production (process) examines the conditions of origin and the production structures of visual communication (Müller \& Geise, 2015). It is trying to understand when, why and how people create and use a visual image (Rose, 2016). For instance, to explore the practices of how visual images are introduced, authors of this thematic issue directly engaged with the producers themselves through interviews and ethnographies. These production aspects also interrelate with the affordances of the platforms used as highlighted in Rose's conceptual framework. The site of the image itself and its content explores the meaning of the visual image by examining the substance as well as the motif of the image (Müller \& Geise, 2015; Rose, 2016). The main question here is, what is displayed in the picture and how?

Our own work in the field of visual social media mainly focuses on the site of the production and the site of the image itself. The methodological framework we have developed is theory-based, investigating use of Instagram for the purpose of strategic communication (see Russmann \& Svensson, 2016). It asks whether organizations that use Instagram focus on one-way information and self-presentation, or whether they engage in two-way communication to establish and cultivate a relationship between themselves and the public. For instance, we have conducted a content analysis of postings, including the visual image, its captions and comments, on the Instagram accounts of Swedish political parties (Filimonov, Russmann, \& Svensson, 2016; Russmann \& Svensson, 2017).

The site(s) of circulation concern why and how visual images are shared and distributed across a platform or platforms. With the shift towards digital media, the importance of research on the circulation of visual images has increased tremendously, not least due to the rise and importance of algorithms mining users' behaviour in order to tailor the circulation of online content (such as advertising for example). This also has a bearing on the site(s) of the audience, which deals with examining forms, structures and processes of the perception and reception of visual images as well as its effects on the audience (Müller \& Geise, 2015). It is important for social media researchers to ask, "how people make sense of the visual in using social media" (Hand, 2017, p. 215)it is about finding answers to questions of who interprets how which visual images with what effects.

The articles presented in this thematic issue of $\mathrm{Me}$ dia and Communication primarily focus on the production of images and their content, and to a lesser degree on the circulation of the visual images and their audience. However, as mentioned above, the four sites intersect and the articles also address the challenges that this brings for researchers. All the authors approach their topics qualitatively, but collectively they demonstrate a variety of different methods. What we can see is that when "we think qualitatively about specific images, observable streams and images, particular contexts of visual social media use and engagement, or the meaningful activities of producing, consuming and distributing images, then we tend toward the recalibration of established interpretative methods in the social sciences and humanities" (Hand, 2017, p. 227). Authors of this thematic issue underline this by relying on content, semiotic and discourse analyses as well as interviews and participant observation.

A question, which has not been addressed in this thematic issue, but needs further discussion, is the ethical commitment of researchers (see also Highfield \& Leaver, 2016). During the process of putting this thematic issue together, authors and reviewers addressed this topic 
on several occasions. Of course, ethics is always a topic when it comes to the use of an individual's data for research purposes, including visual data. The question is not only how we collect, research, store and archive data, but also to what extent do we display the visuals of others in our presentations and publications. The latter is particularly important as visuals (as discussed above) provide another, arguably richer, source of information than written text, which may raise different privacy concerns (see Highfield \& Leaver, 2016). Working on this thematic issue, a frequently asked question was whether we as researchers have the right to display the visual data of our objects of investigation (see also the discussion in Laestadius, 2017). You will find that some authors have not included the analysed visual images whereas others have. Of the authors who included visual images in their articles, some displayed them fully and some depicted sensitive "things" in the visual image. In these cases, the producers of the visual images (pictures) themselves had deliberatively made them accessible to the public across different platforms - often without password protection. Still, it should be discussed to which extent they were aware of the possible in-depth analyses of their pictures in this academic setting. On the other hand, uploading visuals online often entails losing control over the visuals, how they will travel and in which contexts they will be seen. Hence, should faces be glitched or blackened in general? As one reviewer highlighted: "Individual users might object to having their photos used without consent, others might not want their account to be given attention to, others might be pleased by it and explicitly ask to be mentioned by name". The authors of the articles of this thematic issue of Media and Communication have handled this topic differently, and we as editors have not provided any guidelines other than the guide provided by the Association of Internet Researchers Ethics Working Committee (see https://aoir.org/wpcontent/uploads/2017/01/aoir_ethics_graphic_2016.pdf and https://aoir.org/reports/ethics2.pdf).

\section{Articles in This Thematic Issue}

This thematic issue invited contributions on visual communication in social media that focus on developing a conceptual apparatus and precise definitions of objects and practices of study as well as contributions that address and discuss the methodological challenges and their potential solutions. The idea was to synergize research from a wide variety of communication-related disciplines on this rather new topic.

Åsa Thelander and Cecilia Cassinger (2017) start off the thematic issue by exploring how we relate to and perceive a place through Instagram images. The authors explore the place branding campaign of the Swedish municipality Landskrona involving Instagram takeover to imaging the city differently. Instagram take-over means that different citizens managed the city's Instagram account and, hence, giving the follower's an impression of their view of the city. The study does not focus on images themselves, but on the practices of photography though everyday communication technology. The authors aim to develop an understanding of how non-professional visual images are produced, used, and shared on Instagram for strategic purposes to form and strengthen a place's brand. Åsa Thelander and Cecilia Cassinger (2017) use a practice approach to photography where the focus is on the performative aspect. In-depth interviews were carried out with participants in the Instagram takeover project. The procedure can be defined as photoelicitation interviewing; implying that the photographs are serving as input for the interviews, although they are not analyzed per se. Based on the photo-elicitation interviews, the authors form and compare three ideal types of performances labelled as the acting tourist, the Instagrammer, and the professional. Åsa Thelander and Cecilia Cassinger (2017) conclude that when using Instagram for branding purposes it does not necessarily mean that novel visual images are generated, but that they are choreographed according to the affordances of Instagram as a medium.

In addition, Karin Liebhart and Petra Bernhardt's (2017) article focuses on Instagram, particularly its strategic use as a campaign tool in the 2016 Austrian federal presidential election by analyzing the Instagram account of the successful candidate Alexander Van der Bellen. The authors focus on the visual component of digital storytelling. Liebhart and Bernhardt (2017) used an image type analysis in order to reconstruct underlying selection and presentation routines as well as visual strategies. The image type analysis, a research method that was originally developed for the analysis of photo-journalistic routines and selection criteria, allows researchers to classify visual content as specific image types according to their motifs. The authors examined the broad range of visual imagery from photographs, graphics, animated graphics (gifs), image-text combinations as well as short videos that were posted on Alexander Van der Bellen's Instagram account during the election campaign. The study identifies different visual image types that are central to strategic visual self-presentation, for example, of political candidates.

The article by Irmgard Wetzstein (2017) focuses on Twitter and the visual discourse of the 2014 Hong Kong protests (the so-called umbrella movement) on the widely used hashtag \#honkongprotest. Using a documentary image interpretation, the article explores visual thematic patterns, depicted actors and relations among actors, the visual perspectives used as well as visual image sources and narrative strategies. The aim of the empirical study is to analyze the way discourses are formed and structured through visual images and how the visual documentation of a protest movement is shared through Twitter. The study is based on: a) an understanding of visuals as cultural products, which provide knowledge about the "world" and generate meaning by making things visible or unseen, as well as b) on a con- 
cept of discourse referring to the sociology of knowledge. The concept of discourse aims to grasp collective knowledge repertoires, as Irmgard Wetzstein (2017) describes it, "thereby using a broad understanding of knowledge including daily-life theories, internalized everyday practices, stereotypes and routines".

Collaborative meaning-making of visual images on social media platforms is also in the focus of Maria Schreiber's article (2017), albeit with a focus on the individual. Visual communication on and in social media is understood as practices with pictures on platforms. The author introduces a framework, which aims to identify practices, pictures and platforms in order to understand habitual patterns of picture sharing and meaning-making within social media. Practices, i.e. the context and framing of the picture, are analyzed through qualitative methods such as interviews and ethnographic accounts. Pictures are examined on the levels of content and compositional structure. Interfaces, defaults and affordances are considered when focusing on platforms To introduce and test the framework, two screenshots from Instagram and Facebook are analyzed on all three levels. Screenshots contain and show communicative practices and give us access to an in-depth understanding of mediated and multimodal communication.

Mona Kasra (2017) discusses the implications of social media image activism in her article. The article focuses on the meaning (formation) and impact of digitalnetwork images that increasingly function as a novel venue for political advocacy and engagement. Therefore, Mona Kasra (2017) undertakes an in-depth analysis of the 2011 self-published nude self-portrait of Aliaa Elmahdy, a young Egyptian woman. She applies semiotic analysis using Barthes' (1980) theoretical concept of the rhetoric. However, the meaning of Elmahdy's image is also dependent on the engagement of others through their multiple and immediate comments. Here, the author uses the concept of participatory narratives. Participatory narratives reflect a dialectic relationship between individuals and digital technology that takes expression across social media. Her findings highlight the autonomous and participatory nature of digital-network images and their role in perpetuating activism. The online circulation of digital-networked images inspires everchanging and overarching narratives, broadening the contextual scope around which visual images are traditionally viewed.

The exploration of self-portraits or "selfies" in the research process is also addressed in the last article. Katie Warfield (2017) is taking a different, rather "open" approach to studying visual social media when compared with the previous contributions. Based on a pilot study of selfie-taking processes through the methods of phenomenological interviews and photo elicitation, the author reflects on her research troubles and limitations and she re-matter-ializes one of her interviews using new materialist methods (intra-views and post-human visual methods) to reveal data that would otherwise not have been evidenced via her original more humanist-oriented methods. This reflection shows how the material-discursive-affective assemblage, or the arrangement of the interview room, such as the lighting in the room or the available props in the room, the technologies of data recording, the cellphone camera and the available imaging filters, and embodied interactions of the participants all matter in the production of research data. Thereby, the author highlights the importance of looking at the intra-action or entanglement of the different research entities such as participants, research methodology, recording tools, data, and researcher. Specifically, when it comes to exploring selfietaking processes it is not enough to only look at the spoken data. The article ends by highlighting the benefits (for both data collection and reflection) of a post-human approach to intra-views and new materialist informed photo elicitation.

In addition, Laura Kerslake and Rupert Wegerif (2017) provide a book review of Marcel Danesi's book The Semiotics of Emoji: The Rise of Visual Language in the Age of the Internet. The book review gives a short critical overview of Danesi's new work and highlights the central role of emoji in online visual communication.

In summary, the articles within this thematic issue of Media and Communication provide new perspectives and the authors demonstrate how conceptual, theoretical and methodological challenges in visual social media research can be addressed and overcome. Through the use of qualitative approaches, the authors provide in-depth analyses of (the use of) visual content and the meaning of such visual images. It is important for the research process that researchers keep in mind that these analyses are often more time consuming than those of text-based social media communication. These articles add to our understanding of visual communication in the age of social media. However, they also raise new questions and call for further theoretical and empirical research such as on the influence of different affordances. As this thematic issue shows, the questions and the methods used by researchers in the analysis of visual communication in the age of social media vary considerably and are strongly influenced by their respective professional origins (see also Müller \& Geise, 2015). This openness in this rather new research field has to be perceived as being a strength (Müller \& Geise, 2015), and a continuing interdisciplinary conversation on these matters will help to better capture, reveal and understand the production, the visual image itself as well as its impact, its circulation on social media, and the audience's image-related practices. We hope this thematic issue of Media and Communication will contribute and stimulate such academic conversations.

\section{Conflict of Interests}

The authors declare no conflict of interests. 


\section{References}

Barthes, R. (1980). Rhetoric of the image. In A. Trachtenberg (Ed.), Classic essays on photography (pp. 269285). New Haven, CT: Leete's Island.

Fahmy, S., Bock, M. A., \& Wayne, W. (2014). Visual communication theory and research. A mass communication perspective. New York, NY: Palgrave Macmillan.

Filimonov, K., Russmann, U., \& Svensson, J. (2016). Picturing the party-Instagram and party campaigning in the 2014 Swedish elections. Social Media + Society, 1-11. doi:10.1177/2056305116662179

Hand, M. (2017). Visuality in social media: Researching images, circulations and practices. In L. Sloan \& A. Quan-Haase (Eds.), The SAGE handbook of social media research methods (pp. 217-231). London: Sage.

Highfield, T., \& Leaver, T. (2016). Instagrammatics and digital methods: Studying visual social media, from selfies and GIFs to memes and emoji. Communication Research and Practices, 2(1), 47-62.

Kasra, M. (2017). Digital-networked images as personal acts of political expression: New categories for meaning formation. Media and Communication, 5(4), 51-64.

Kerslake, L., \& Wegerif, R. (2017). The semiotics of emoji: The rise of visual language in the age of the Internet. Media and Communication, 5(4), 75-78.

Laestadius, L. (2017). Instagram. In L. Sloan \& A. QuanHaase (Eds.), The SAGE handbook of social media research methods (pp. 573-592). London: Sage.

Liebhart, K., \& Bernhardt, P. (2017). Political storytelling on Instagram: Key aspects of Alexander Van der Bellen's successful 2016 presidential election campaign. Media and Communication, 5(4), 15-25.

Müller, M. G., \& Geise, S. (2015). Grundlagen der Visuellen Kommunikation [Introduction to visual communication]. Konstanz and Munich: UVK Verlagsgesellschaft $\mathrm{mbH}$.

Rose, G. (2016). Visual methodologies. An introduction to researching with visual materials (4th ed.). London: Sage.

Russmann, U., \& Svensson, J. (2016). Studying organizations on Instagram. Information, 7(4), 1-12. doi:10.3390/info7040058

Russmann, U., \& Svensson, J. (2017). Interaction on Instagram? Glimpses from the 2014 Swedish elections. International Journal of E-Politics, 8(1), 50-65. doi:10.4018/IJEP.2017010104

Schreiber, M. (2017). Showing/sharing: Analysing visual communication from a praxeological perspective. Media and Communication, 5(4), 37-50.

Thelander, Å., \& Cassinger, C. (2017). Brand new images? Implications of Instagram photography for place branding. Media and Communication, 5(4), 6-14.

Warfield, K. (2017). "I set the camera on the handle of my dresser": Re-matter-ializing social media visual methods through a case study of selfies. Media and Communication, 5(4), 65-74.

Wetzstein, I. (2017). The visual discourse of protest movements on Twitter: The case of Hong Kong 2014. Media and Communication, 5(4), 26-36.

\section{About the Authors}

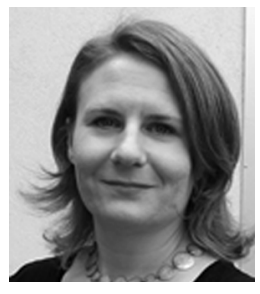

Uta Russmann (PhD, University of Vienna) is a professor at the Department of Communication, Marketing \& Sales at the FHWien der WKW University of Applied Sciences for Management \& Communication, Vienna. Her research interests include online communication, visual social media, public relations, strategic communication, political communication, and media and elections.

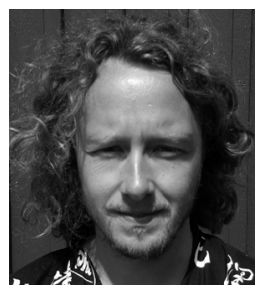

Jakob Svensson (PhD, Lund University) is an associate professor in Media and Communication at the School of Arts \& Communication (K3) at Malmö University (Sweden) where he directs the BA program Media Activism, Strategy \& Entrepreneurship. His research interests include social media and political participation, mobile telephony in so-called developing countries, LGBTQ empowerment in contexts of state-sanctioned homophobia, media logics and algorithms. 